\title{
Ethiopia: \\ The Roles of the Council of Elders (Menguddo) in Gumma Customary Institution of Conflict Resolution
}

\author{
Bamlaku Tadesse MENGISTU
}

\begin{abstract}
This study was conducted on the roles of the council of elders in Gumma customary institution of conflict resolution in the Meiso district of northeastern Oromia regional administration. The main objective was to examine the roles of the council of elders in Gumma customary mechanisms of peace-making with a prime focus on informal indigenous structures. An attempt was made to assess the roles of the council of elders in Gumma customary institution in addressing the political and socio-economic arena, the organisational governance structure of the Gumma system, how it functions and also assesses its judicial procedures in the process of conflict resolution. The paper found out that the Gumma customary institution is most effective and efficient for inter-intra clan conflicts than inter-ethnic conflicts. The processes of Gumma in addressing conflicts involve a series of ritual practices that aims to reintegrate the unity of the community which was broken down and fractured due to past atrocities. People are obedient to this customary system. As a result of this, people seem keen not to protract hostilities that may eventually divide the community members. It is through their elders and community leaders that the important issues pertinent to the unity and social stability will be addressed. The Meiso area Oromo clans have the council of elders (Menguddo) through which inter-clan conflicts are sorted out and thoroughly addressed. The local assemblies function as customary courts whose rules and regulations derive from shared norms and mutually binding value systems. The paper concludes that while the customary system is
\end{abstract} an efficient means of dealing with conflicts in the study area, an integration of the customary and modern systems is needed for sustainable peace and development in the region.

Keywords: Gumma system, customary institution, conflict resolution, Oromo clans, eastern Ethiopia.

\section{Introduction}

Customary institutions are informal local institutions developed and maintained by the local community members for centu-

\section{Bamlaku Tadesse MENGISTU}

Dean, Faculty of Leadership and Governance

Studies, Department of Peace and Conflict Studies

FDRE Melese Zenawi Leadership Academy

E-mail:

Conflict Studies Quarterly

Issue 26, January 2019, pp. 32-52

DOI:10.24193/csq.26.3

Published First Online: 05/01/2019 
ries that corresponds and adheres to the society's norms, values, principles and sanctions. Such customary institutions include local cultural forms of organisation (like a clan), locally elected, appointed, or hereditary leaders and community elders. They have customary rules and regulations as well as indigenous practices and knowledge regulating the access to and ownership of resources by each member of the community (Watson, 2001).

In most sub-Saharan African countries, the unsuitability between modern laws and customary rules can be held through the concept of legal pluralism (Benda-Beckmann, 2001). While modern institutions are backed up by state legislature, customary institutions include kin networks, local cultural, administrative structures, customary land tenure rules, as well as conventions about marriage, inheritance or trade and customary procedures to resolve conflicts over resources. Customary institutions are more important where there is unpredictability of environments and unclear with regard to resource tenure, ownership rights, and ethnic identity (Krätli \& Swift, 2001).

Furthermore, most pastoralists in the Horn of Africa have well proved and effective indigenous mechanism of preventing, mitigating, managing and resolving conflicts at grassroot level. The efficiency and effectiveness of such customary institutions draw the attention of the governments of the Horn of African countries to mainstream and adopt these indigenous mechanisms to make the region more stable and peaceful. If the roles of customary institutions in addressing conflicts in the region are diminished, things would have been exacerbated and gone out of the government's control and been developed to a full scale of conflict between the neighbouring states and ethnic/clan groups. When compared with the non-customary institutions for the prevention and resolution of conflicts, they are less complex, save time and give chances to parties in conflict to actively participate to resolve their own problems and to handle their affairs in relatively more acceptable way to them with their own language, norms and values (Sisay, 2008). They have the power to redress and heal the wounds due to the past atrocities made on the conflicting parties, cool down the grievances systematically and finally addresses the root causes and triggering factors of conflicts.

The Meiso area Oromo clans (Ittu, Alla, Nolle, Obera) have their own customary institutions which are responsible for the prevention, resolution and management of conflicts and the access, ownership and management of communal natural resources for long centuries. Such customary institutions are headed and run by the council of elders (Menguddo). The main focus of this paper is how the council of elders in Gumma customary institution resolves various types of conflicts including the ritual procedures, the amount and the types of compensations during the conflict resolution processes. It also addresses how the council of elders in Gumma institution is traditionally organised as a governing structure and how the different governing bodies are appointed or elected in the Gumma system. The Gumma customary institution among the Oromo is the commonly practised system which will be discussed in detail below. 


\section{Research Methodology}

\subsection{The Study Site}

This study selected the Ittu pastoralist groups in Meiso district, West Hararaghe Zone of Oromia Regional state in eastern Ethiopia where there is the prevalence of recurrent ethnic/clan conflicts. The study area is one of the most affected by the impacts of recurrent conflicts and drought conditions in Ethiopia, in particular, and the Horn of Africa, in general, which hampered to sustain the traditional modes of pastoral livelihoods. The study area is largely arid and semi-arid with high temperatures and low precipitation. Given the dominance of pastoralism and an ongoing shift towards settled agriculture, dependence on rainfall is more obvious and stronger today than in the past. The region has suffered a series of recurrent catastrophes (such as conflicts, droughts and famines) for the last four or more decades. The 1984/85, 1999/2000 and 2004 drought episodes, described by some as the worst in recent memory, led to numerous deaths both of human lives and livestock species (Devereux, 2006). Such recurrent events in the area also led to the occurrence of widespread poverty and displacement of many pastoralists which affects all sections of the community irrespective of age and sex.

The study area has also experienced a change in land use, i.e. from communal grazing land ownership to privately owned land for crop farming and closure areas for drought periods. The natural resource degradation is also accelerating due to the impact of population pressure, climate change and variability, and among others. These, in turn, aggravate the scarcity of natural resources in which the (agro) pastoralists primarily depend on. Such acute shortage/scarcity of resources leads to the stiff competition between (agro) pastoralists for access and ownership rights.

\subsection{Sampling Design and Method of Data Collection and Analysis}

The study has employed qualitative based case study in which data were collected using semi-structured key informant interviews, focus group discussions, personal observations and informal discussions. These methods of qualitative data collection have been identified as appropriate (Yin, 2003) and used to collect data on the roles of the council of elders in Gumma in resolving conflicts, its judicial procedures and how compensations during the resolution process is addressed. Two kebeles (the lowest administrative unite) were selected purposively based on the severity of recurrent conflicts and drought. In-depth interviews with key informants were conducted and data generated in order to have a thick description of how the council of elders in Gumma customary institution is addressing inter-intra clan conflicts. Key informants were selected purposively based on their sex, age and awareness/knowledge about their culture, society and environment. Purposive and snowball sampling techniques were employed to select the key informants from each kebele. The number of key informants (a total of 16 consisting of six females and ten males) was adjusted after factors and conditions 


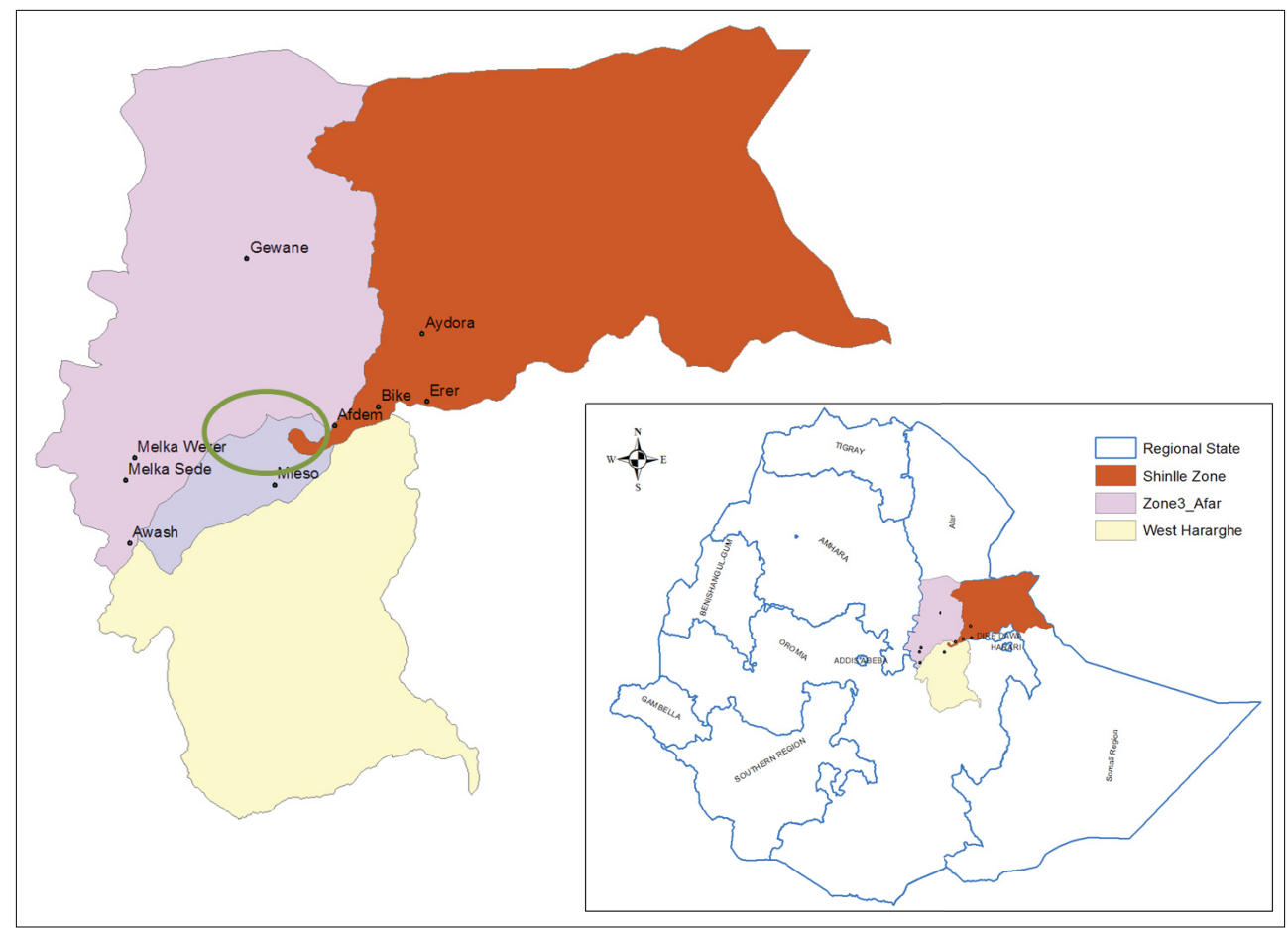

Figure 1: Map of the Study area (Meiso district with blue colour)

became clear and directive while the study was in operation. In addition, a total of 6 focus group discussions (three focus group discussions in each kebele, one with men, one with youth and another with women) were conducted to generate data for the purpose of understanding how the council of elders in Gumma system and its procedures, compensation mechanisms and ritual ceremonies are functioning. The focus group discussion participants were selected purposively based on their sex, age and awareness about their culture. In addition to collecting primary data, there were also systematic examinations of relevant documents - both published and unpublished from both the district, zone and regional offices which includes as reports, peace agreements, joint collaborative works on peace building and conflict prevention, resolution and management as secondary data sources.

Concerning with the analysis of qualitative data, the research was based on the theoretical and methodological principles of subjective interpretations (i.e. Grounded Theory). To this effect, a content analysis technique was employed to analyse the qualitative data. The analysis technique targets at organising and reducing the empirical data into themes or essences through analytical induction. Qualitative data analysis is a process of making sense of data through uncovering themes, concepts, insights, patterns, categories, perceptions and understandings. The analysis involves an iterative, inductive and reduc- 
tive process of formulating conceptual ordering for data is called coding that facilitates conditions for the constructing themes, essences, descriptions and theories (Walker \& Myrick, 2006). According to Miles and Huberman (1994), qualitative data analysis involves three macro processes. These are data reduction (extracting the essence), data display (organizing for meaning), and drawing conclusions (explaining the findings).

\section{Result and Discussion}

\subsection{The Council of Elders in Gumma Customary Institution among the Oromo}

The council of elders in Gumma customary institution of conflict resolution, justice administration and peace-building is able to carry out its purpose for long centuries and is still functional to the communities at large. As an indigenous conflict resolution mechanism, it is playing significant roles in bringing the conflicting parties together and discuss the problems at stake to acknowledge each other's perspectives and deal for mutual benefits. Gumma has the ability to manage and heal the wounds, psychological and social traumas of the victims while the state legal systems fail to manage such issues. As a mechanism, priority is given to the reconstruction of social and psychological traumas created by the conflict. The ideology of the state legal system in Ethiopia is drawn mainly from the Western legal philosophy which is highly predisposed by an individualistic orientation and does not fit the strong social orientation and commitment on the ground where it is being implemented. This idea precisely exemplifies Ethiopia's legal system's neglect of the psycho-social aspects of conflict resolution, justice administration and peacebuilding. In other words, the state legal systems attempt to bring about retributive justice by simply punishing the criminal person while the council of elders in Gumma strives to bring about restorative justice by focusing on restoration of the fractured psychological and social capital as a result of homicide at various levels. Restoring interpersonal, intergroup or intercommunity relationships and reintegrating delinquents into their communities are important goals of any sustainable conflictresolving, justice-doing, and peace-building process as the council of elders in Gumma system is doing. Edossa and his acquaintances make a good point of inquiry about the importance of customary institutions such as the Gadaa system in managing conflict, particularly conflict that emanates from access to natural resources (Edossa, Babel, Gupta, \& Awulachew, 2005). Therefore, it is imperative that the council of elders in Gumma institution practice restorative justice that state courts and legal practitioners are unable to bring restorative justice among the disputants. It can be considered as an alternative strategy to a state legal system. It is retributive in nature since it can manage the likely cycles of vendetta arising from homicide.

In addition, the council of elders in Gumma institution is part of the complex and holistic nature of the Gadaa system that encompasses the political, social and economic aspects of the Oromo people. The Gadaa system is a complex institution that the Oromo people have been practising since time immemorial to deal with the impediments and workings 
of their communal lives (Assefa, 2008). According to Sisay (2008:53), "The Oromo have one of the most open and democratic cultures among Ethiopians. Their system of African Democracy known as Geda is a well-known African indigenous political system that governs social order, politics, as well as peaceful conflict resolution". Here, the council of elders in Gumma and the Gadaa systems are not independent to each other. Gumma is simply a sub-set of the bigger Gadaa system. In other words, while the council of elders in Gumma system focuses more to conflict issues, the Gadaa system deal with the social, cultural, political and economic aspects that infuses all aspects of their day to day life.

\subsection{Traditional Governance Structure}

\section{of the council of elders in Gumma System}

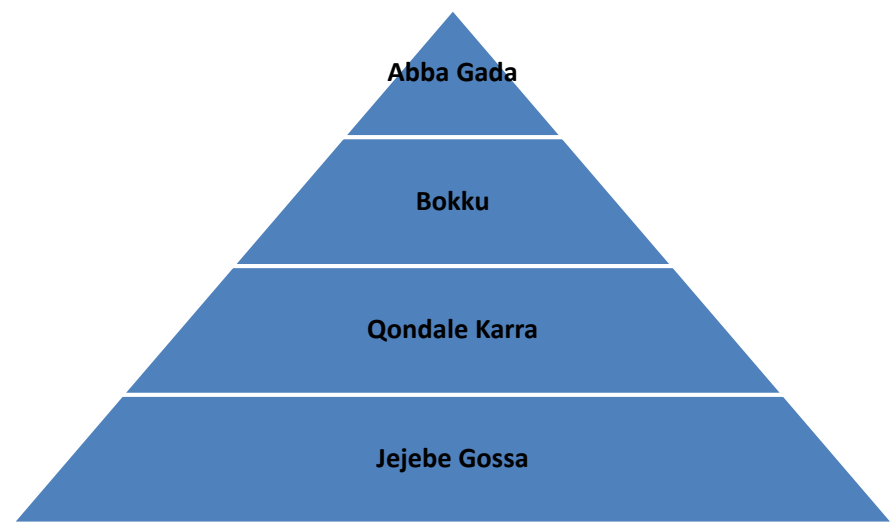

Source: Field Inquisition

The council of elders in Gumaa customary governance structure has the capacity of creating a conducive environment so as to ensure justice among the communities. The fair treatment of the disputants according to the rules and regulations of the council of elders in Gumma system is primarily based on the core principles of narrations and reflections on the misdeeds of one over the other. The narrations, arguments and counter-arguments among the disputants help the parties come to a revelation of root causes of their conflicts, acknowledgement of apologies for atrocities, and particulars of bad experiences the parties acquired from the conflict (Karbo \& Mutisi, 2008).

The governance structure of the council of elders in Gumma system is hierarchical in its structural, administrative and governing principles and procedures. There are different hierarchical positions with their own duties and responsibilities to discharge in accordance with the rules, procedures and regulations of the council of elders in Gumma system. Each position has its own duties and responsibilities which are directly accountable to the immediate next top position in the Gumma governance structure. For example, the Abba Gada is the head of the council of elders in Gumma system who 
hold the top position in the council of elders in Gumma customary governance system. The Abba Gada is in charge of responding to all walks of life that affects the smooth operations of the council of elders in Gumma system which have a direct impact on the wellbeing of his subordinates including resolving conflicts. The next most top position is the Bokku(s) who is/are equated in modern governance system as minister(s) who has different duties and responsibilities in the community. It is also named as Damina in Arabic word which means representative to the respective clan/village members. Next to the Bokku is the Qondale Karra who is responsible for the fair distributions of resources and contribution of the compensations supplied from members of each clan during conflict resolution processes. The next most important position is the Jejebi Gossa which is the lowest position in the council of elders in Gumma governing structure. Jejebi Gossa is normally a soldier (s) who is/are responsible for enforcing the decisions made by the council of elders (Menguddo) in the Gumma administration. They are responsible for collecting cattle for compensation, punish, whip or any other form of retribution against the criminal at grass root level in kebeles or small level administrative units. They are also responsible for disseminating all types of information channelled from the top position ( $A b b a$ Gada) down through those hierarchical positions to the community members at grass root level.

This system of governing violence and conflicts is preferred by most community members over the state legal system for a number of reasons. To mention, the council of elders in Gumma system takes shorter period, has low cost, cases are handed near to their homesteads (not expected to travel long distances to find out courts), parties can speak and address their cases with their own languages, and among others. This point of argumentation is in line with the work of Meron (2010) about the court of sheikhs. The authors underline the advantages of customary institutions over the state legal system and also the doubts of the public at large about the effectiveness and trustworthiness of the state legal system. The author further underlined that the longer time state courts require for processing a case, the high amount of expenses incurred at the state court, the unnecessary emphasis on testimony and verification, and the possibility of corruption are some of the reasons for the preference for customary institutions such as the sheikhs' court over the state-based legal system (Meron, 2010).

\subsubsection{The Electoral systems and procedures under the council of elders in Gumma governance structure}

Jejebi Gossa is the lowest administrative unit in the council of elders in Gumma governance structure that acts as a messenger for Qondalla Karra at the village level, elected based on their efficiency on their duties and responsibilities. They should be strong enough, young and energetic to go everywhere in the fastest way to collect cattle for compensation. They are elected by the Qondalla Karra. They should have a special skill in persuading people and collect money and/or cattle for compensations besides to their physical strength. 
Qondalla Karras (the next top position to Jejebi Gossa) are also elected by the Abba Boku based on their merit. The special selection criteria to be a Qondalla Karra are the one who has tolerance, orator skill, respected by others, genuine and trustworthy, and the like. Before the final election, the potential Qondalla Karras will be nominated by the Abba Boku. They will be assigned by the Abba Boku for different responsibilities for a certain period of time to test their strength, efficiency, skill, acceptability by the community and other qualities. If the Abba Boku wants to nominate three Qondallas, there will be four to six potential candidates that will be assigned to the different positions to testify their qualities. The potential candidates will be presented to the community for nomination/voting and out of the four to six potential candidates, only three (the intended ones) who performs best and got the highest voting will be nominated and finally approved by the Abba Boku in front of the community members. In that day there will be celebrations of ritual ceremonies. In that day one well-fattened ox will be slaughtered for the ceremony and all the community members will participate and enjoy that festivity. The Abba Boku then introduces the elected Qondallas for each community and empowered them by blessing. The elected Qondallas will be blessed by the Abba Boku and other community elders by saying "If you bless someone who accepts your instructions and act accordingly, he will be blessed and on the contrary, if you curse someone who refuses you, he will be cursed".

Abba Boku (the next top position to Qondalla Karra) is elected by the Abba Gada for each clan based on their merit. The numbers of the Abba Boku are based on the number of clans in West Hararghe zone of Oromia regional state. They are representing their own respective clans in the assemblies of the council of the Abba Gada.

And finally the Abba Gada will be elected for eight years from all the potential candidates who perform well and got the highest voting. The Abba Gada is also elected based on merit at a place called Odda Boltum near Gelemso. The Abba Gada should have special qualities like tolerance, knowledgeable, knows the culture of the West Hararghe Oromo people, respected by all the community members, descent, and orator skill. If the Abba Gada is elected from one clan for the first rounds of eight years, then the next Abba Gada will be elected from another clan on competitive basis. For the West Hararghe zone, there is one Abba Gada. For the election process, each clan from all the districts in West Hararghe zone sent their potential candidates at Odda Boltum for nomination to be an Abba Gada. At Odda Bultum a temporary house will be constructed for this purpose since the election ceremony lasts for several days. There are also ritual ceremonies. Oxen will be slaughtered for the ceremony; and there will be chants, songs and festivities.

Unlike the Borena and Guji Oromo clans in southern Ethiopia, the Abba Gada of the West Hararghe zone Oromo clans is not hereditary. This is because according to the community elders, they have different clan groups while the Borena and Guji have only one clan (Borena and Gujji clan). In Borena and Guji the Abba Gada is nominated from 
one specific family which is hereditary. In Borena and Guji, the next Abba Gada will be trained, well informed and share experiences from the current Abba Gada before the termination of his period. Such practice is impossible in the study area Oromo clans because the next Abba Gada will not be identified or unknown while the current ones is still in power as it is not hereditary. The Abba Gada is elected in every eight years, but the Abba Boku and Qondalla clan administrators go beyond eight years based on their performance. The Abba Gada will be deported from power if he committed a mistake/ crime during his ruling period. Jejebi are assigned for administration for temporal periods in times of crises only.

The different Oromo clans in eastern Ethiopia identified themselves and belong to one of the members of the several clan groups by counting/tracing to their apical ancestors through their father's line. This is because membership to a certain clan group is solely counted through the patrilineal descent family as these pastoral communities are patriarchal. In a patriarchal (agro) pastoral community where there is the domination of males over females in all aspects (including property inheritance and transfer, ownership, access/use rights), females after marriage belong to their husband's clan group. In accordance to this principle of patrilineal descent system, the Oromo generally classified as Borena and Barentu. The Borena lived in the south, southwestern and western parts of Ethiopia while the Barentu lived in the southeastern, eastern and northeastern parts of Ethiopia.

\subsection{The Procedure of the council of elders in Gumma Customary System in Resolving Conflicts}

The Meiso area Oromo clans have their traditional ways of conflict resolution in both intra-inter clan conflicts. In the process and procedures of conflict resolution, first the council of elders named Menguddo who have ample experiences, knowledgeable, and orator skill that can persuade others is appointed to address the case. In the procedure of the council of elders in Gumma customary system, the Menguddo should be an independent third party from another clan as a mediator between the disputed parties/clans. The independent third party, the mediator now takes their cases and become responsible for handling the matter according to the laws and procedures of the council of elders in Gumma customary system. They first identify the problem what is at stake and then tries to address those problems that need immediate attention. For instance, if there are murder or wound cases, these should be first addressed/handled properly before the council of elders tries to embark on other aspects of the conflict resolution process.

Then, the delinquent will be handed over to an independent third party of another clan member until the case is handled by the council of elders (Menguddo). These independent third parties who host the murderer voluntarily on temporary bases are referred to as mediators. No one knows where the mediator hides the criminal, to the 
extent that his families don't know where he is. Once the criminal is handed over to the mediators, there will not be revenge actions as he is departed from his family and clan members in the form of refugee/custody. After this initial Gumma ceremony has been performed, it is customary that by no means there will be any form of retaliatory actions of one over the other for the purpose feuding.

Then after this initial and binding resolution ceremony, the elder's council set a larger appointment for resolving their conflict at clan level by involving members of the two clan groups. This takes long periods of time so that the delinquent's clan members will have ample time to get ready for the compensation. This is known as Agajimma (literal meaning- time of preparation for the resolution process). It takes for a month up to three months. If they are not ready to pay on the first appointment date, the elder's council will set another appointment and this will continue for three times in readjusting the appointment date. Sometimes the appointment period will be extended up to six months if there is prolonged drought which forces the pastoralists and their cattle away from their homesteads for longer periods for water and pasture. Even sometimes it will be extended for a year if there are socio-political instabilities in the area beside to drought. This hinders the clan members of the delinquent to collect the required numbers of cattle for compensation.

Then, the Abba Boku instructs the Qondallas to collect the required amount of cattle for compensations. The Qondallas called an urgent meeting with the delinquent clan members termed as Mamulti to form a committee called seglen (nine in number) so as to collect cattle for compensation from their own clan members.

Then, the delinquent will be assigned to look after those cattle contributed by his clan members for compensation until the committee members finished their duty. Till that time (the date of final resolution), the perpetrator is obliged to pass all the sanctions and punishments based on the peace accords of the council of elders in Gumma customary governance system which are believed to be good lessons for the other clan members. To mention some of the social sanctions that his community members imposed on him because of his guiltiness are as follows:

He is isolated from his community members and not allowed to do communal activities. He is also isolated from his family, he is not allowed make love with his wife, not allowed to eat and drink together with people since he is considered as impure (as his hands are dirty with blood), forced to eat and drink with broken dishes/utensils, he is allowed to get in to (out) home at backyards only as if he is robber, he is not allowed to cut his nail short, not allowed to cut his hair short, not allowed to wash his body and clothes, and among others.

These procedures and sanctions are all symbols and ways of punishing the delinquent. Then after the seglen finished the preparation and when the appointment date ap- 
proaches, a large temporary tent (locally named as dass) that has shade and accommodates all clan members of both sides will be constructed in the homestead of the delinquent's family. This is because all the expenses related to the conflict resolution process and ritual ceremonies including chat, cigarettes, food, and the like should be covered by the delinquent's clan besides to the expenses related to compensation and funeral ceremonies. This huge amount of expenses and burden at different stages of the resolution process on the delinquent's clan members is considered as a lesson for others not to repeat this type of mistake again. Before the two clan members entered in to the huge tent, they will seat under the shed of the near bye tree to discuss all the matters, express all the grievances and worries, accusations and counter-accusations, charges on wrongdoers, etc so that all misdeeds and mistakes should be addressed under the shed in front of the traditional jurisdiction. The jurisdiction listens to the accusations raised by the deceased families in connection to the murder of their son. After thoroughly discussing all the issues, accusations and counter-accusations from both sides, the mediators together with the conflicting parties will go directly to the temporarily constructed huge tent. Then the elders instruct the delinquent's family to present one selected (top-ranked) ox - named as Feyissa Garri which will be given to the Qondallas of the deceased clan. It will not be counted on the total number of contributed cattle for compensation.

Once they entered in to the tent, it is strictly forbidden to raise charges, complaints, accusations and counter-accusations of one over the other. There are also rules and regulations on the seating arrangement of the conflicting parties (the two clan members) at the temporarily constructed huge tent. The deceased clan members will seat on the right side while the delinquent's clan members will seat on the left side of the tent. This has its own implications. That is in Oromo culture if someone who offends others (murder, theft, insult, etc), there is the saying that elders will enforce him to bring a guarantor and stood at the left side (not on the right side). Its implication is the left side represents that they fell as if they are inferior, wrongdoers, criminals, and the like while the right side represents they are faithful, normal, superior, they are considered as a king, and the like. At the middle, an independent third party (the mediators) will seat. Both parties will be served food independently.

The huge temporary tent has two gates. If someone who serves the audiences with food/meat entered in the right part of the gate, then another clan representative who serves the audiences will enter the gate on the opposite side. And both of them will serve both clan members and should go out of the tent on the opposite side of their entrance. They should not return back to their entrance gate. This indicates that once the contending parties reached a consensus and eat together under one tent, they should not raise complaints, charges, and accusations and counter-accusations rather they should strengthen their friendship and peaceful coexistence. It is considered as one family, no more revenge and blood feud, and the like. They are not allowed to intermarry to each 
other. In all these days where the ritual ceremony has performed, the delinquent is imprisoned inside the kraal together with the cattle collected for compensation.

On the morning of the next day, the audiences of the two clan members will be served with roasted meat. Then it is followed by the ritual ceremony on the delinquent himself. The delinquent who looks after the cattle for compensations for several months and now imprisoned at the nearby kraal with the cattle will be allowed to come out to the audience tied with a rope at his right hand together with difin qill (unbroken and unprepared traditional vase like drinking pot/container containing bitter test). The symbolic interpretation of this unbroken qill tied on his right hand is the bitterness of assassinating someone irrespective of the different causes. The assassination of someone (usually at his right hand except for left-handed individuals in rear cases) and its subsequent public exclusion and serious punishment are equated with the bitter taste of the fruits of this traditional container (qill). The fruits of murder have also bitter taste, grief, apprehension, guiltiness, frustration, mental illness and the like for the delinquent.

The Qondalla of the delinquent clan is now allowed to stand in front of the large audiences and speak loudly by saying this "Please allow me to go to the water points, grazing areas, participate in public affairs and festivities, etc. freely as the delinquent was isolated from the public affairs for several months". He repeats these words loudly three times to the audience. Then, the Qondalla of the deceased clan responds to this call three times by saying this "I forgive you and permit you to go to the water points and grazing areas freely".

This is what we call forgiveness in conflict resolution processes. Until this time, the delinquent was not allowed to go to the grazing areas and water points. But now this permission allows him to access both resources and participate in all public affairs freely and equally. Again the Qondalla of the delinquent clan also shouts three times loudly by saying "Please break this bitter and unbroken qill from the hand of the delinquent". Then, the Qondalla of the deceased clan responds loudly three times by saying "I broke it".

After this public solemn promise, the deceased family members took all the animals contributed for compensation from the kraal. Then, now the delinquent will be allowed to stand in front of the large audience so as to beg them and make him free from all of these sanctions and forgive him for his transgression. Then, again the delinquent tied together with the brother of the deceased by a rope made of leather (locally named as Meditch $a)^{1}$ and came together in front of the large audience. Community elders and religious leaders will now bless them to be united as one and become brothers as they tied together and came close to each other. The right hands of the delinquent

1 The Medicha rope is made of a skin from the ox taken from the legs around their wrist. 
and deceased brother will be tied with this Medicha by an independent third party elder's representative, named as Menguddo Amba (also termed as Faji Amba) and all their close relatives will stand behind them accordingly. The Meditcha that tied them together symbolises that they are now united together and their enmity came to an end for peace and development. Then, it is followed by a statement of community elders by saying like this:

From this time onwards the two individuals/clan groups are no more enemies rather they are brothers, same clan members and the like. It is also declared that one group should allow and welcome others to their own territory, home and homestead at all times (during crises, good times and at other times). From this time onwards, it is also considered as having five cattle in common, i.e if an individual from either member of the two clans killed someone from another third clan/ethnic group, the two clans should contribute the five cattle for compensation as if they are members of the same clan. At this juncture they agreed that they will help each other during compensations, crises, and even funeral ceremonies. All these statements are loudly declared in front of the large audience. It is also cursed if someone violates this agreement and the curse will be up on him if someone breaks all these agreements.

The deceased mother will lash butter on the hair of the belligerents (particularly the close relatives of the delinquent and the deceased). In turn, the delinquent's mother will come holding milk with a traditional drinking pot called qill so as to drink her son (the delinquent) and the deceased brother. And then, the delinquent and the deceased brother will also serve each other with honey which shows that their enmity/bitterness should be get rid of from their body and replenish themselves with sweat, love and friendship. Again the delinquent's mother brings butter and lashes on their chest so that the evil spirit will disappear from their heart and in turn good hopes replace their thoughts and feelings. They also give each other one heifer. Finally, they will go to one of the two houses to eat and drink together and then repeat it to the house of the second one. This indicates that their agreement and forgiveness is real since eating and drinking together is considered as a sign of love and friendship. The symbolic interpretation of this ceremony is that the butter that lashes on their head and chest will get rid of evil spirits from their womb or mind and begun as relatives rather than enemies. It is also a customary norm that from that time onwards, they are not allowed to inter-marry among themselves since they are considered as close relatives by that resolution process.

The delinquent then went to a hillside. Here, his eye brow will be cut short, the difin qill (the traditional and natural drinking pot) tied to his right hand will be broken down, his nail cut short, he will be allowed to change his old clothing with a new one, he is allowed to eat together with people, and those utensils who used during his confession 
time will be broken and buried in that hill. This is followed by slaughtering a sheep at his family's home and he will be blessed at this ceremony by his close relatives. These all symbolises that the evil spirit attached to and encouraged him for murder will be now dispossessed from him and buried with these all things. Then, it is believed that he is now becoming normal and will be allowed to join the community. This seclusion process may last for about one to six months and sometimes more depending on the seasons in which this process takes place.

After the delinquent is becoming "clean" by these ritual ceremonies, all his utensils that serve him food and drink during his custody will be broken down and thrown away which indicates the beginning of new life, hope, peaceful coexistence and love with others. Compared to the modern system of conflict resolution, the customary system of resolving conflicts is more solemn, cumbersome, and gives good lessons that instruct individuals. All the above-mentioned sanctions are more difficult and tiresome not only for the delinquent but also to his families/clan members compared to the modern system. In the modern system, if someone commits a crime, he will be simply imprisoned and he has the right to be visited by his relatives, make love with his wife and the like. Focus group discussants added that if a baby is conceived when his father is at jail committing a crime, it is believed that the baby will also repeat by committing the same crime as his father did. This is because it is believed that the spirit attached to the father will pass on to the baby during the time of conception at the mother's womb.

Women's role in customary conflict resolution practice is a continuation of their domestic burdens. Their participation is restricted only to serving the council of elders with food and coffee during the resolution process. However, without their presence the resolution process will not be performed because if they are not part of the process and not observing the decision process, they will instigate another conflict. Women are not directly participated in conflict resolution process. There is a saying in Oromo culture that women's and children's cases are not handled under a tree (as if their cases are simple and hence it can be solved at home by their neighbours) and they cannot address complex societal issues under a tree by themselves. This implies how patriarchy in this society is deeply embedded in their culture that restricts women's community role and also their cases are believed to be simple in its scope and complexity. Here, the shed of a tree doesn't mean a simple tree/shed rather the traditional courtroom in which disputes and various social, political and economic issues are discussed and handled. Therefore, a tree shed symbolizes justice, fairness, equality, and the like.

These long and time taking procedures of the council of elders in Gumma system are targeting for the reconstruction and rebuilding of the fractured social cosmos and regain the unity and oneness of the community in disputes. The system enables to achieve this through the arrangement of continuous negotiations and argumentations so as to repair the wounds of the socio-psychological traumas occurred as a result of the 
conflicts. It closely scrutinises the conflicting parties, treats their fear and frustration, and repairs the societal cracks. The crucial goal of any customary conflict resolution mechanism is socio-psychological reintegration, reestablishment of community relationships and reunification of delinquents into their communities (Karbo \& Mutisi, 2008) by stimulating emotional attachments of the conflict parties. The council of elders in Gumma system is, therefore, to restore the social, moral, and psychological values of the community damaged by the conflict. Although council of elders in Gumma most of the time addresses cases of vendetta, revenge, blood price or compensation, feud, and the ritual aspects of purification that follows homicide (Dejene, 2002), it can generally be seen as a compensation and purification process that follows a conflict.

Therefore, these procedures and ritual ceremonies are primarily meant for peace-building strategies that are used to restore violated social rules and detached emotional attachments through full confession, honest remorse and sincere apology, rather than through the mere restitution of and compensation for lost life or property. Through this system, there will be the recovery of the normal social space by restoring the wrinkled socio-psychological assets that are embedded in the societal cultural values by performing ritual ceremonies altogether. The system also has the capacity to effectively restore the social bonds and oneness of the conflicting parties (at this time communities of conflicting parties) by reintegrating them in their social, psychological and moral values. It has the ultimate supremacy to impede conflicts reduce (and if possible eradicate) hostilities, revenge killings; reduce the polarizations of disputants; and ultimately restore peace and harmony among the communities with its legitimate power.

According to the theory of structural functionalism, many scholars have accepted that dispute processing involves rituals. The pioneering studies of Durkheim show that rituals have the power of reinforcing collective emotion and forming group cohesion. If group cohesion is fractured and broken down due to violence and conflicts among the rival groups, performing such rituals among these parties have the power to restore their cohesion and oneness. This view of Durkheim was adopted by later structuralfunctionalists who have emphasised the role of rituals in supporting the survival of the larger system (Seymour-Smith, 1986). The structural functional theory is one of the major theoretical approaches to the study of conflict. Nader (1968) shows that this theory emphasizes both the structural sources and the structural functions of conflict. Lewellen (1983) states that the structural functionalists view society as an equilibrium system whose component parts play a role in the maintenance of the whole. Hence, as part of social life, conflicts too work towards the maintenance of the ongoing social structure and hence conflict is considered as a normal process of social life. The works of Evans-Pritchard (1940) 'The Nuer' and Gluckman's 'Custom and Conflict in Africa' (1956) are typical examples of such an approach, which dominated the period between the 1940s and 1950s in legal anthropology (Lewellen, 1983). 
Furthermore, Gluckman (cited in Lewellen, 1983, p. 9) stated that rituals are not simple means of expressing feelings but also symbols that emphasise the priority of the system over the individual. By the same token, Hoebel (1966) describes that rituals are acts, which are believed to maintain the status quo or to achieve the specified ends. Turner (1969) provides powerful attributes to the anthropological emphasis upon the importance of synchronisation. His work shows what role rituals play in achieving and enhancing oneness, in his term 'communitas'. For Turner, the law is an antithesis of communitas, whereas dispute settlement is a way of restoring the oneness. This means, state legal system is unable to restore societal cohesion unlike that of the customary institutions that mainly depends on ritual ceremonies.

Ritual ceremonies for Turner (1957) are social drama that resolves crises by dramatising the advantages of cultural values and social arrangements. It is performed in response to the breach of law during times of conflicts to restore the fractured social order. Through rituals, social values are given sacred authority. According to him, the social drama of dispute settlement processes passes through four phases. First, there is the breach of peace when there are criminal acts committed by individuals during the occurrence of conflicts. Second, the crises that result from the breach in which the social cohesion and stability is fractured as a result of the violations of social norms, values, principles and sanctions. Third, there is the practice of resolving the crises with the help of customary institutions involving ritual practices. Such customary institutions have their own rules and procedures in conflict resolution, justice administration and peace-building efforts. Fourth, the re-establishment of the unity of the groups after the application of ritual ceremonies which restore the wounds of the society incurred due to conflicts.

This Gumma system is functional only in the intra-clan conflicts among the Oromo. They didn't have such systems for cases of inter-ethnic conflicts except for few cases. This system works for conflicts between Oromo clans and Hawiya clan (as Hawiya affiliated with the Oromo and the Oromo considered the Hawiya as one of their clans), but doesn't work for conflicts between Oromo vs Issa and Oromo vs Afar conflicts. The only way of addressing the latter types of conflicts is through the intervention of the modern system of conflict resolution, i.e. through the intervention of the federal army which is almost ineffective and not timely as the community elders pointed out. Article 34(5) of the Constitution of the Federal Democratic Republic of Ethiopia limits the mandates of customary and religious institutions issues related to private and family civil cases. They handle various issues of conflict cases ranging from civil to criminal offences that arise from intra/inter-clan and intra/inter-ethnic conflict (Meron, 2010, p. 81). Gumma is one of these customary institutions that has been and is currently functional in handling cases of homicide in the study area, but no roles with the conflicts between Oromo and Issa Somali and limited roles with that of Oromo and Afar. 


\subsection{Compensations for Different Types of Offenses in the council of elders in Gumma System}

The Oromo clans in the study area have its own rule of governance for various maladjustments and happenings, particularly with conflict and conflict resolution practices. Compensation or blood money also called Gumma is one of the best strategies in indigenous institutions of conflict resolution mechanisms. The term Gumma in this research has two meanings/applications in the study area. First, it refers to compensation/blood money. Gumma is most often used to refer to compensation/blood money and rites of refinement and purification following a homicide and this meaning is much more common among the population. Second, it stands for an institution responsible for addressing conflict cases. The word Gumma used to refer to the general institution of settling blood feuds between two persons, families, groups, clans, communities, or even nations (Dibaba, 2012). According to Dejene (2002), the term Gumma, however, has multiple meanings when it is alone and in combination with other words in different parts of Oromia. For instance, 'Warra-Gumma' means parties at blood feud; 'GummaBaasuu' means killing for vengeance; and 'Gumma-Nyaachuu' means getting blood price. In short, Gumma is an indigenous institution of settling blood feuds between parties (Warra-Gumma). In the study area, there are strict rules and regulations for every kind of offences with regard to compensation mechanisms of the Gumma customary institution though it is challenged by the impacts of modernisation. The youth group who invested less or not at all in the Gumma customary system is more reluctant for its rules and principles particularly with issues of compensations. Youth group are more influenced by the impact of globalisation and modernisation. Some of the compensations for offences are as follows:

First, if the killing of an individual happens suddenly, the amount of compensations given to the deceased family is hundred cattle. If the killing of an individual is planned and/or purposive, the amount of compensations will be increased to one hundred fifty cattle.

Second, the amount of compensations for the offence of an amputation/destruction of any of the body parts has its own specific rules and regulations by the Gumma customary law. For example, there are clearly identified customary laws and regulations for the amputations of arms and legs, deletions/removal of eyes, destruction of teeth, etc. to compensate the offended one.

Concerning the amputation of arms, the amount of compensations for the right and left hand is quite different for its own socio-cultural reasons. For example, if the left hand is amputated, the amount of compensation given to the offended one is sixteen cattle and if the right hand is amputated, fifteen cattle will be given (one more cattle is added for the left-hand amputation because the left hand is considered as more important than the right one because of its role in reproduction/love making and defense mechanisms). 
Besides, the variation also occurs in legs amputations. If the left leg is amputated, the number of compensations given to the offended one is sixteen cattle, two oxen and one mule; while if it is the right leg, the compensation will be fifteen cattle, two oxen and one mule. Here, two oxen are given for the injured one for farming purpose and one mule for transportation as his leg is injured.

In the case of eliminations of someone's eye (s), nineteen cattle for each eyes or sometimes it is equated with a gift of few cattle and a virgin girl to look after and guide him as a wife and a form of a gift (compensation) will be given for the offended one. If the man refuses to accept her (the virgin girl) as a gift, her clan also regrets and asks why he refuses her, i.e the question of clan identity/recognition by other clan members. Compensation for women is generally smaller than men for such cases of similar offences and a man who creates the problem on a woman will be forced to marry her. If someone insults a woman/girl as blind or any other injury related insults, he will be punished seriously.

If the offended party is unable to pay the decided amount of cattle, there are enforcement mechanisms in the form of social exclusion from any social affairs in their own respective clans. Similarly, if the husband crashes one of the teeth of his wife, he will not be punished. But, if he insults her in connection to her teeth that he broke, he will pay five cattle to her family.

The third type is compensations related to rape cases. Focus group discussion participants pointed out that let alone rape cases if someone harassed a woman/girl verbally, he will be punished seriously. Several years ago, girls were not being harassed and dared by men/boys rather they were respected. In connection to their compensation, hundred cattle will be given for killings, five cattle for rape cases; rape of someone's wife involuntarily is five cattle and voluntarily is one cattle for the husband. Voluntary and involuntary rape cases are identified on the style of their sleeping whether it is by force or on peaceful means. For rape cases the compensation various from case to case. For a virgin girl it is five cattle, and for none virgin girl is three cattle.

Fourth, if someone killed somebody while he is on offensive acts, there will not be Gumma ceremony for that. This is justified that anyone has the right to defend himself/ his family from any external enemy as a result he will not be considered as criminal according to their customary system. It is not also considered as an offensive act against someone. Finally, for looting cases if some loot one cattle, he will be forced to return back one additional cattle.

\section{Conclusion}

The paper tried to address the importance of cultural processes, institutions, and values that involves ritual practices in customary forms of conflict resolution and peacebuilding among the Oromo of Meios district in eastern Ethiopia through the well-established 
Gumma system. The essential goal of any customary forms of conflict resolution mechanism is socio-psychological reintegration, reestablishment of community relationships and reunification of delinquents into their communities (Karbo \& Mutisi, 2008) by stimulating emotional attachments of the conflict parties. This could be possible through performing ritual practices that can facilitate for the restoration of societal cracks. The council of elders in Gumma system is, therefore, to restore the social, moral, and psychological values of the community damaged during the conflict. It is evident in the study community that most individuals, families and communities still prefer customary forms of conflict resolution processes because they are based on cultural concepts, values, and procedures that are understood and accepted by the community. People are familiar with their cultural underpinnings (norms, values, principles and sanctions) and therefore it is easier to come to compress with responsibilities that emanate from such foundations. It is in this principle that the customary courts with the guidance and operations of informal procedures, laws, rules and regulations which are more approachable and understandable by the local people at large, work efficiently and effectively. It is in this context that the principles of social cohesion, harmony, openness/transparency, participation, peaceful co-existence, respect, tolerance and humbleness, and among others, are emphasised as core issues in customary conflict resolution mechanisms among the Oromo community in Meiso area.

The customary forms of conflict resolution practices take place in a way that address the complex web of economic, social and political arenas so as to shun total societal disintegration in the aftermath of elders' decisions. In a dynamic and changing world, the challenge of customary practices in addressing conflict issues will continue in the (post) modern era. This is due to a multitude of factors including the ability of customary structures to challenge old norms and values systems that constitute the statuesque; and the extent of honesty and transparency in customary institutions to engage in reforms to accommodate new realities. Modernization that impacted on the value systems of customary institutions and creates gaps in the transfer of indigenous knowledge into successive generations will result in the dilution of the importance of customary conflict handling approaches.

\section{References:}

1. Assefa, J. (2008). Applying Gada principles in constructing the state in the 21st century Oromia. In A. Adugna (Ed.), Proceedings of the 2007 Oromo Studies Association Annual Conference held at the University of Minnesota Coffman Memorial Union Great Hall (pp. 25-41). Minnesota: Oromo Studies Association.

2. Benda-Beckmann, F. (2001). Legal Pluralism and Social Justice in Economic and Political Development. Institute of Development Studies Bulletin, 32(1), 46-56.

3. Dejene, G. (2002). Some aspects of conflict and conflict resolution among Waliso Oromo of Eastern Macha, with particular emphasis on the Guma. Unpublished M.A. Thesis, School of Graduate Studies, Addis Ababa University, Addis Ababa, Ethiopia. 
4. Devereux, S. (2006). Vulnerable livelihoods in Somali Region, Ethiopia. Brighton: Institute of Development Studies (IDS), University of Sussex.

5. Dibaba, A. T. (2012). Theorizing 'Waadaa' as a non-violent principle in Salale: Confronting law without justice. Addis Ababa: Oromo Folklore and Resistance Studies.

6. Edossa D. C., Babel, M. S., Gupta, A., \& Awulachew, S. (2005, January 26-28). Indigenous systems of conflict resolution in Oromia, Ethiopia. International workshop on African water laws: Plural legislative frameworks for rural water management in Africa, Johannesburg, South Africa.

7. Evans-Pritchard, E. E (1940). The Nuer: A Description of the Mode of Livelihood and Political Institutions of Nilotic People. New York: Oxford University Press.

8. Gluckman, M. (1956). Customs and Conflict in Africa. Basil: Blackwell Publisher Limited.

9. Hoebel, E. A. (1966). Anthropology: The Study of Man. New York: McGraw Hill Book Company.

10. Karbo, T. \& Mutisi, M. (2008, October 2-4). Psychological aspects of post-conflict reconstruction: Transforming mindsets: The case of the Gacaca in Rwanda. A paper prepared for the Ad Hoc Expert Group meeting on Lessons learned in post-conflict state capacity: Reconstructing governance and public administration capacities in post-conflict societies, Accra, Ghana.

11. Krätli, S. \& Swift, J. (2001). Understanding and Managing Pastoral Conflict in Kenya: a literature review. Brighton: Institute of Development Studies.

12. Lewellen, T. C. (1983). Political Anthropology: An Introduction. New York: Bergin and Garvey.

13. Meron Z. (2010). Ye Shakoch Chilot (the court of the sheikhs): A traditional institution of conflict resolution in Oromiya zone of Amhara regional state, Ethiopia. African Journal on Conflict Resolution, 10(1), 63-82.

14. Miles, M. B., \& Huberman, A. M. (1994). Qualitative data analysis: An expanded sourcebook (2nd ed.). Thousand Oaks, CA: Sage.

15. Nader, L. (1968). "Conflict: Anthropological Aspect”. In International Encyclopedia of the Social Sciences, 3, (pp. 230-241). New York: Macmillan Company and the free press.

16. Seymour-Smith, C. (1986). Macmillan Dictionary of Anthropology. London: Macmillan Press.

17. Sisay, A. (2008). The challenge of establishing democratic governance for development in Ethiopia and the Horn of Africa: The critical role of the Oromo in the development of Ethiopia. In A. Adugna (Ed.), Proceedings of the 2007 Oromo Studies Association Annual Conference held at the University of Minnesota Coffman Memorial Union Great Hall (pp. 52-76). Minnesota: Oromo Studies Association.

18. Turner, V. (1957). Schism and continuity in an African society. Manchester: Manchester University Press.

19. Turner, V. (1969). The Ritual Process: Structure and Anti-Structure. Chicago: Aldine Publishing Company.

20. Walker, D., \& Myrick, F. (2006). Grounded theory: an exploration of process and procedure. Qualitative Health Research, 16(4), 547-559. 
21. Watson, E. (2001). Preliminary Research Findings from Borena, Oromia Region, Ethiopia. Marena Research Project Working Paper no. 4. Cambridge: University of Cambridge

22. Yin, R. K. (2003). Case study research: Designs and methods (3rd ed.). Thousand Oaks, CA: Sage. 